\title{
Application of the Care Bundle in Perioperative Nursing Care of the Type A Aortic Dissection
}

\author{
$\mathrm{Li} \mathrm{Li}^{\mathrm{I}-3}$ \\ Jiangqi Zhou ${ }^{3}$ \\ Likun Luo ${ }^{3}$ \\ Xiaoqing Chen ${ }^{3}$ \\ Yinglan $\mathrm{Li} \mathbb{1}^{2,4}$ \\ 'Xinjiang Medical University,Urumqi, \\ 830000,Xinjiang, People's Republic of \\ China; ${ }^{2}$ Nursing School, Xinjiang Medical \\ University,Urumqi, 830000, Xinjiang, \\ People's Republic of China; ${ }^{3}$ Operating \\ Room, The First Affiliated Hospital of \\ Xinjiang Medical University, Urumqi, \\ 830000, Xinjiang, People's Republic of \\ China; ${ }^{4}$ Xiangya Nursing School, Central \\ South University, Changsha, 410000, \\ Hunan Province, People's Republic of \\ China
}

Correspondence: Yinglan $\mathrm{Li}$ School of Nursing, Xinjiang Medical University, Xuelianshan Campus of Xinjiang Medical University, No. 567 North Shangde Road, Hemaquan New District, Shuimogou District, Urumqi, 830000, Xinjiang, People's Republic of China

Email yuyan0202@sina.com
Background: To investigate the effect of the care bundle in the nursing care of the type A aortic dissection (TAAD).

Methods: A total of 161 patients with TAAD were included in the study. They were divided into control group $(n=79)$ and care bundle group $(n=82)$. The patients in the control group received routine nursing, while the patients in the care bundle group received routine nursing and care bundle. IL-2, IL-6 and IL-10 levels in the three periods of T0 (before anesthesia), T1 (before anesthesia to $6 \mathrm{~h}$ after surgery) and T2 (6-24 h after surgery), intraoperative blood loss, postoperative recovery, ICU stay time, intraoperative pressure ulcer rate, postoperative delirium rate, bloodstream infection rate and doctor satisfaction.

Results: The postoperative $\mathrm{T}$ and $\mathrm{pH}$ levels in two groups were all in the normal range. The levels of IL-2, IL-6 and IL-10 in the care bundle group at different periods were also significantly different. The levels of IL-2 and IL-10 showed an increased trend, while that of IL-6 showed a downward trend. The intraoperative blood loss, postoperative recovery and ICU stay time, intraoperative pressure sore rate, postoperative delirium rate, and bloodstream infection rate were lower, whereas doctor satisfaction was all significantly higher in care bundle group.

Conclusion: Care bundle increased the safety of the operation, and it was beneficial to the postoperative rehabilitation for TAAD patients.

Relevance to Clinical Practice: Patients with TAAD who underwent operation need higher quality care during the entire operation. Cluster nursing is the kind of the nursing model that can better meet the requirements of the intraoperative nursing quality. The intervention methods in this study include 5 core nursing measures. These measures are implemented together in a synergistic manner to effectively improve the quality of nursing care in operating room and the health outcomes of patients with TAAD. Care bundle is worthy of clinical application.

Keywords: care bundle, nursing care, type A aortic dissection

\section{Plain Language Summary}

What is the contribution of this study to the wider global clinical community?

1. Care bundle is beneficial to nursing care of TAAD treatment.

2. Care bundle can effectively promote the recovery of patients.

3. Care bundle is worthy of clinical application.

\section{Introduction}

Acute aortic dissection (AAD) is a pathological change with a double-lumen dissection (true and false lumen). AAD can be divided into type $\mathrm{A}$ and type $\mathrm{B}$ according to the 
Stanford classification. ${ }^{1}$ Type A aortic dissection (TAAD) involves the ascending aorta with rapid progress. $^{2}$ Epidemiology studies show a statistical incidence in Europe of approximately 2-16 cases/100,000 inhabitants/year. ${ }^{3}$ The 48-h mortality is about $50 \%$, and the 2-week mortality is about $75 \% .{ }^{4}$ TAAD has a wide range of lesions involving many important organs. Currently, surgery is still the recommended treatment for TAAD. However, it is difficult to operate, and has a relatively high incidence of postoperative complications. ${ }^{5}$ The most common predisposing factor for AAD patients is hypertension, and nearly $80 \%$ of $\mathrm{AD}$ patients suffer from hypertension. ${ }^{6}$ During the perioperative period, it is necessary to stabilize the patients' blood pressure to reduce the sheer force of the blood flow on the aortic wall. In the Guidelines for Diagnosis and Treatment of Aortic Diseases issued by the European Society of Cardiology in $2014^{7}$ it has pointed out that in early phase of AAD, if systolic blood pressure (SBP) is controlled at $100-120 \mathrm{mmHg}$ and heart rate (HR) is controlled at $60-70$ beats $/ \mathrm{min}$, it can prevent further expansion of interlayer tears and reduce mortality. Moreover, inflammatory response also plays an important role in the formation of AAD. ${ }^{8-10}$ IL-2, IL-6 and IL-10 are important indicators to evaluate the immune status of the body. IL-2 has anti-tumor and anti-infection effects through participating in the activation and proliferation of $\mathrm{B}$ lymphocytes and the proliferation of cytotoxic T cells. ${ }^{11}$ During the pathogenesis of TAAD, IL-6 infiltrates the aortic wall and eventually lead to a systemic inflammatory response. ${ }^{12}$ IL-10 is a multi-potent antiinflammatory cytokine secreted, which can inhibit tumor necrosis factor $\mathrm{C}$ and other cytokines secreted by Th1 subtype cells. ${ }^{13}$

The key to successful surgery depends not only on the surgeon's skill, but also on the quality of care. Therefore, the operating room nursing team faces certain challenges. The intraoperative pressure ulcers are more likely to occur due to the relatively unstable circulation status of patients with $\mathrm{AD}$ during surgery and the long operation time. ${ }^{14}$ Implementing skin protection measures for $\mathrm{AD}$ patients is an important nursing measure to prevent postoperative infections and promote postoperative recovery.

The concept of the care bundle was firstly proposed by the Institute for Healthcare Improvement (IHI, USA) in 2001. ${ }^{15}$ It points out that the care bundle includes 3-5 evidence-based, interrelated, simple and operable practice measures. At present, care bundle has been applied to prevent ventilatorassociated pneumonia and central line-associated bloodstream infection, and has achieved significant effects. ${ }^{16,17}$ Huang et $\mathrm{al}^{18}$ applied the care bundle to the preoperative care of AAD patients and found that it significantly reduced the incidence of $\mathrm{AD}$ rupture. However, the effect of care bundle in the nursing care of TAAD in entire surgical treatment process is still unclear. Therefore, the purpose of this study was to investigate the effect of care bundle in the nursing care of TAAD.

\section{Methods}

\section{Subjects}

The study was conducted in accordance with the Declaration of Helsinki and reviewed and approved by the Ethics Committee of the Xinjiang Medical University. Written informed consent was obtained from every patient. A total of 161 patients with TAAD who underwent surgery in the Xinjiang Medical University from January 2018 to December 2019 were included in the study. According to the time we performed different nursing care, 79 patients who underwent surgery from January 2018 to December 2018 were considered as control group, and 82 patients who underwent surgery from January 2019 and December 2019 were considered as care bundle group. They underwent total arch replacement and ascending aortic replacement. The patients in the control group received routine nursing, while the patients in the care bundle group received routine nursing and care bundle. Inclusion criteria: 1) patients who met the diagnostic criteria of acute TAAD ${ }^{19}$ (2) patients who received surgical treatment; (3) patients with acute TAAD caused by hypertension. Patients combined with other diseases were excluded.

\section{Routine Care}

Briefly, one specialist nurse was arranged to cardiac operating room. The patient's SBP was reduced to $110-120 \mathrm{mmHg}$ before surgery, and no time limit was set. The heating blanket was adjusted to $36^{\circ} \mathrm{C}$ for rewarming until the anal temperature was $\geq 36^{\circ} \mathrm{C}$. A foam dressing was applied for skin protection according to the condition of the patient and the operation time.

\section{Care Bundle}

\section{Multidisciplinary Collaboration}

The treatment group consisted of cardiac surgeons, anesthesiologists, CBP technicians, specialist nurses, material specialists and ICU nurses. ${ }^{20}$ Combined with the admission process of AD patients and the supply of surgical materials, the reasons for the failure rate of operation were summarized based on brainstorming method. After literature search and screening and multiple revisions, a feasible care bundle plan was made. 


\section{Emergency Initiation}

The green emergency channel was activated for $\mathrm{AD}$ patients. The surgeon informed the operating room and the anesthesiology department to coordinate the operating room and prepare the surgical materials $1 \mathrm{~h}$ in advance, and then the specialist nursing team members were responsible. They had completed the constantly updated learning plan as scheduled with multimedia, video, MOC and other learning channels.

\section{Blood Pressure Control}

A quiet and comfortable environment was provided. With the goal of "quiet, painless, SBP of 110 to $120 \mathrm{mmHg}$, HR below 70 beats/min", $\mathrm{AD}$ patients were required to lower their blood pressure to the target value within 5 to $10 \mathrm{~min}^{21}$ In the perioperative period, the blood pressure management model of the integration of surgeon, nurse and patients ${ }^{22}$ was implemented. During the transfer process of AD patients, medical staff should cooperate with each other to reduce waiting time, closely observe the condition, shorten the transfer path, and handle it carefully.

\section{Body Temperature Modulation}

Multiple pre-warming measures were used to adjust the patients' body temperature, including opening the 100level operation room $30 \mathrm{~min}$ before the operation and adjusting the temperature to $22 \sim 24^{\circ} \mathrm{C}^{23}$ The medical electric blanket or water circulation heating blanket was placed on the operating bed. The inflatable insulation blanket was placed under the patient's lower limbs. When the CBP began, the room temperature was adjusted to $18-20^{\circ} \mathrm{C}$ and an ice cap was used. When the CBP stopped, the room temperature was adjusted to $24-26^{\circ} \mathrm{C}$. After the temperature of the anal canal raised to $32^{\circ} \mathrm{C}$, the ice cap was removed and the electric blanket or heating water blanket and inflatable insulation blanket were turned on. The set temperature of the blanket should be $5^{\circ} \mathrm{C}$ lower than the patient's rectal temperature to avoid low-temperature burns. Heated wet dressing was used if necessary. Meanwhile, the infusion warmer was adjusted to $36-37^{\circ} \mathrm{C}$ to heat input fluid until the temperature of the anus or the nasopharynx was $\geq 36^{\circ} \mathrm{C}$.

\section{Skin Protection}

The special skin care included evaluation of pressure ulcers, laying cotton pads, applying colloids, adhering dressings, moderate lifting, dynamic inspection and handover inspection and restoring normal body temperature. Foam dressings were applied to the head, shoulders, sacral tail and heels that are prone to pressure sores. ${ }^{24}$ If possible, patients were gently lifted for $10 \mathrm{~min}$ at an interval of about $1 \mathrm{~h}$.

\section{General Indicators}

The values of HR, SBP, diastolic blood pressure (DBP), core temperature $(\mathrm{T})$ and $\mathrm{pH}$ were recorded before and after operation. Blood pressure was measured by puncturing the left and right radial artery and dorsal plantar artery. HR was read by pulse oxygen. $T$ indicated nasopharyngeal temperature or anal temperature. $\mathrm{pH}$ value was measured using the blood gas analyzer. Intraoperative blood loss was calculated based on the blood container and dressing blood storage. Intraoperative pressure ulcers were assessed according to pressure ulcer

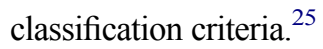

\section{Enzyme Linked Immunosorbent Assay (ELISA)}

Peripheral venous blood $(3 \mathrm{~mL})$ was collected at three time points of T0 (before anesthesia), T1 (before anesthesia-6h after operation) and T2 (6-24 h after operation). Plasma was obtained after centrifugation. Quantitative determination of the levels of IL-2, IL-6 and IL-10 in plasma was performed by ELISA.

\section{Surgical Prognostic Indexes}

Postoperative recovery time referred to the time from the end of operation to the recovery of patients' consciousness. ICU stay time was the period from the end of operation to transferout from ICU. Confusion Assessment Method for the Intensive Care Unit (CAM-ICU) was used to determine the incidence of delirium in postoperative patients. ${ }^{26}$ According to the postoperative axillary temperature $>37.5^{\circ} \mathrm{C}$ and abnormal blood items, the postoperative blood flow infection was determined according to the postoperative axillary temperature of $>37.5^{\circ} \mathrm{C}$ and the abnormal results of blood routine examination.

\section{Doctor Satisfaction Survey}

The questionnaire for doctor satisfaction developed by $\mathrm{Du}$ et $\mathrm{al}^{27}$ was used. The reliability and validity of the questionnaire were both greater than 0.7 . It contained 5 items, including material supply, professional technology, work efficiency, emergency handling, and communication and collaboration. The Cronbach's coefficient was 0.802. Satisfaction was divided into very satisfied, satisfied and dissatisfied. Totally, 29 questionnaires were issued and 29 were returned, with a recovery rate of $100 \%$. 


\section{Statistical Analysis}

Statistical analysis was performed using SPSS 25.0 statistical software package. The measurement data with normal distribution were expressed as means \pm standard deviation (SD) and analyzed using paired independent sample $t$-test or ANOVA. The counting data were described as frequency and analyzed using $\chi^{2}$ test or Fisher's exact test. A $P$ value less than 0.05 was considered as statistically significant.

\section{Results}

\section{Comparison of the Indicators Before and} After Operation

There were 130 males and 31 females. They were aged $42-$ $68(51.36 \pm 7.12)$ years old. There were no significant differences in the clinical data between the two groups (Table 1). Moreover, there was no significant difference in HR between the two groups $(P>0.05)$. The levels of SBP and DBP before and after operation were statistically different between within-groups and between the two groups $(P<0.05)$. There were no statistical differences in $\mathrm{T}$ and $\mathrm{pH}$ between within-groups $(P>0.05)$. However, the differences in postoperative SBP, DBP, $\mathrm{T}$ and $\mathrm{pH}$ between the two groups were statistically significant $(P<0.05)$ (Table 2$)$. These results indicated that the care bundle intervention was conducive to stabilizing the basic indexes.

\section{Comparison of Interleukin Levels}

\section{Between the Two Groups}

To explore the inflammatory response, serum interleukin levels were measured by ELISA. At T1, the levels of IL-2 and IL-10 in the care bundle group were higher than those in the control group, while IL-6 level was lower than the control group $(P<0.05)$. The levels of IL-2, IL-6 and IL-10 at $\mathrm{T} 0, \mathrm{~T} 1$ and $\mathrm{T} 2$ in the care bundle group were statistically different $(P<0.05)$. The levels of IL-2 and IL-10 showed increasing trends, and IL-6 level showed a downward trend. There were no significant differences in the levels of IL-2 and IL-10 between T1 and T2 $(P>0.05)$. There were no significant differences in the levels of IL-2 and IL-6 in the control group among the

Table I Comparison of the General Information of the Two Groups

\begin{tabular}{|l|l|l|l|l|}
\hline Clinical Information & Care Bundle Group & Control Group & $\mathbf{t} / \chi^{2}$ & $\mathbf{P}$ \\
\hline Age (years old) & $53.75 \pm 6.03$ & $51.30 \pm 4.57$ & 0.760 & 0.389 \\
\hline Sex & & & & \\
Male & 68 & 62 & 0.551 & 0.303 \\
Female & 14 & 17 & & \\
Body mass index $\left(\mathrm{kg} / \mathrm{m}^{2}\right)$ & $26.16 \pm 4.49$ & $25.42 \pm 2.65$ & 0.627 & 0.433 \\
History of hypertension & $71(86.6)$ & $67(84.8)$ & 0.824 & 0.461 \\
History of diabetes & $2(2.4)$ & $3(3.8)$ & 0.678 & 0.482 \\
History of cardiovascular surgery & $1(1.2)$ & $1(1.3)$ & 1.000 & 0.742 \\
Preoperative APACHE II score & $14.30 \pm 1.45$ & $14.85 \pm 1.53$ & 0.005 & 0.942 \\
\hline
\end{tabular}

Abbreviation: APACHE, acute physiology and chronic health evaluation.

Table 2 Comparison of Indexes Between Within-Groups or Between Two Groups Before and After Operation

\begin{tabular}{|l|l|l|l|l|l|l|}
\hline Group & Time & HR/min & SBP/mmHg & DBP/mmHg & T/ ${ }^{\circ} \mathbf{C}$ & $\mathbf{p H}$ \\
\hline Care bundle group & Before operation & $73.85 \pm 3.73$ & $161.55 \pm 4.58$ & $91.25 \pm 5.79$ & $36.81 \pm 0.53$ & $7.40 \pm 0.04$ \\
& After operation & $74.40 \pm 5.79$ & $110.34 \pm 5.97^{*}$ & $72.05 \pm 3.62^{*}$ & $36.87 \pm 0.46^{* *}$ & $7.39 \pm 0.03^{*}$ \\
\hline$t$ & & 9.089 & 38.001 & 18.412 & -1.924 & -0.909 \\
$P$ & & 0.076 & $<0.01$ & $<0.01$ & 0.06 & 0.373 \\
\hline Control group & Before operation & $73.03 \pm 4.22$ & $160.47 \pm 5.98$ & $90.93 \pm 4.56$ & $36.78 \pm 0.54$ & $7.38 \pm 0.08$ \\
& After operation & $74.28 \pm 5.12$ & $111.62 \pm 4.96$ & $72.84 \pm 5.57$ & $36.77 \pm 0.41$ & $7.37 \pm 0.01$ \\
\hline$t$ & & 7.382 & 36.012 & 11.371 & 6.773 & -0.112 \\
$P$ & & 0.231 & 0.016 & $<0.01$ & 0.12 & 0.912 \\
\hline
\end{tabular}

Notes: Comparison of the postoperative indexes between the two groups, $* P<0.05$ and $* * P<0.01$.

Abbreviations: HR, heart rate; SBP, systolic pressure; DBP, diastolic pressure; T, core temperature. 
periods of T0, T1 and T2. However, IL-10 level was significantly different, showing a trend of first increasing and then decreasing (Table 3).

\section{Comparison of the Intraoperative Blood Loss, Recovery Time and ICU Stay Time Between the Two Groups}

To explore the changes of the prognostic indexes of operation, the monitoring of relevant indicators was performed. The intraoperative blood loss, postoperative recovery time and ICU stay time in the care bundle group were significantly lower than control group $(P<0.05)$ (Table 4$)$. These results indicated that the care bundle intervention may improve the prognosis.

\section{Comparison of Complications Between the Two Groups}

The postoperative complications were also evaluated. The intraoperative pressure ulcers, postoperative delirium and postoperative bloodstream infections in the care bundle group were significantly lower than control group
$(P<0.05)$ (Table 5). These results indicated that the care bundle intervention may decrease the incidences of postoperative complications.

\section{Comparison of Doctor Satisfaction Between the Two Groups}

To investigate the satisfaction of doctor with the nursing work, the questionnaire investigation of doctor satisfaction was performed. The ratios of "very satisfied" in the care bundle group and the control group were $75.9 \%$ and $42.4 \%$, respectively $(\chi 2=7.132, \quad P=0.028)$ (Table 6). These results indicated that the care bundle intervention method could improve the satisfaction of doctors.

\section{Discussion}

Our results showed that there was no statistically significant difference in HR before and after surgery between the two groups, indicating that the care bundle intervention had no significant effect on the HR in AD patients. The postoperative SBP and DBP levels in the two groups were lower than the preoperative values, and the postoperative SBP and DBP levels in the care bundle group were lower

Table 3 Comparison of the Interleukin Levels Between the Two Groups

\begin{tabular}{|c|c|c|c|c|c|}
\hline Items & Time & Care Bundle Group & Control Group & $t$ & $P$ \\
\hline IL-2 (ng/L) & $\begin{array}{l}\text { T0 } \\
\text { TI } \\
\text { T2 } \\
F \\
P\end{array}$ & $\begin{array}{l}149.38 \pm 33.23 \\
160.63 \pm 38.93 \\
164.15 \pm 32.9 \mid \\
6.163 \\
0.002\end{array}$ & $\begin{array}{l}|25.98 \pm 36.8| \\
|45.33 \pm 3| .68 \\
\mid 47.48 \pm 36.73 \\
I .897 \\
0.152\end{array}$ & $\begin{array}{l}0.030 \\
5.801 \\
1.829\end{array}$ & $\begin{array}{l}0.863 \\
0.017 \\
0.167\end{array}$ \\
\hline IL-6 (ng/L) & $\begin{array}{l}\text { T0 } \\
\text { TI } \\
\text { T2 } \\
F \\
P\end{array}$ & $\begin{array}{l}51.10 \pm 15.21 \\
43.15 \pm 14.62 \\
45.64 \pm 12.26 \\
6.449 \\
0.002\end{array}$ & $\begin{array}{l}49.02 \pm 16.61 \\
47.75 \pm 15.66 \\
45.04 \pm 14.10 \\
0.895 \\
0.41\end{array}$ & $\begin{array}{l}1.829 \\
7.676 \\
2.396\end{array}$ & $\begin{array}{l}0.178 \\
0.006 \\
0.124\end{array}$ \\
\hline IL-I0 (ng/L) & $\begin{array}{l}\text { T0 } \\
\text { TI } \\
\text { T2 } \\
F \\
P\end{array}$ & $\begin{array}{l}|34.93 \pm 39.5| \\
\mid 56.19 \pm 48.18 \\
\mid 62.23 \pm 46.36 \\
|| .29 \mid \\
<0.0 \mid\end{array}$ & $\begin{array}{l}127.05 \pm 20.94 \\
\mid 43.19 \pm 32.14 \\
127.24 \pm 33.95 \\
15.395 \\
<0.01\end{array}$ & $\begin{array}{l}0.525 \\
10.312 \\
0.111\end{array}$ & $\begin{array}{l}0.471 \\
0.002 \\
0.740\end{array}$ \\
\hline
\end{tabular}

Table 4 Comparison of the Intraoperative Blood Loss, Recovery Time and ICU Stay Time Between the Two Groups

\begin{tabular}{|l|l|l|l|l|}
\hline Item & Care Bundle Group & Control Group & $\boldsymbol{t}$ & $\boldsymbol{P}$ \\
\hline Intraoperative blood loss (mL) & $1761.22 \pm 516.09$ & $2310.76 \pm 641.37$ & 18.138 & $<0.01$ \\
Postoperative recovery time (h) & $16.98 \pm 1.63$ & $22.70 \pm 1.99$ & 6.256 & 0.013 \\
ICU stay time (d) & $6.24 \pm 1.44$ & $12.83 \pm 1.64$ & 4.182 & 0.042 \\
\hline
\end{tabular}


Table 5 Comparison of the Complications Between the Two Groups

\begin{tabular}{|c|c|c|c|c|c|c|c|}
\hline \multirow[t]{2}{*}{ Groups } & \multirow[t]{2}{*}{ Number } & \multicolumn{2}{|c|}{$\begin{array}{l}\text { Intraoperative Pressure Ulcer } \\
(\mathrm{n}, \%)\end{array}$} & \multicolumn{2}{|c|}{$\begin{array}{l}\text { Postoperative Delirium } \\
(\mathrm{n}, \%)\end{array}$} & \multicolumn{2}{|c|}{$\begin{array}{l}\text { Postoperative Bloodstream } \\
\text { Infection (n, \%) }\end{array}$} \\
\hline & & Yes & No & Yes & No & Yes & No \\
\hline Care bundle group & 82 & $4(4.9)$ & $78(95.1)$ & $12(14.6)$ & $70(85.4)$ & $2(2.4)$ & $80(97.6)$ \\
\hline Control group & 79 & $13(16.5)$ & $66(83.5)$ & $21(26.6)$ & $58(73.4)$ & $9(11.4)$ & $70(88.6)$ \\
\hline$\chi^{2}$ & & \multicolumn{2}{|l|}{5.711} & \multicolumn{2}{|l|}{6.464} & \multicolumn{2}{|l|}{5.067} \\
\hline$P$ & & \multicolumn{2}{|l|}{0.015} & \multicolumn{2}{|l|}{0.011} & \multicolumn{2}{|l|}{0.024} \\
\hline
\end{tabular}

Table 6 Comparison of the Doctor Satisfaction Between the Two Groups

\begin{tabular}{|l|l|l|l|l|}
\hline \multirow{2}{*}{ Groups } & \multirow{2}{*}{ Number } & \multicolumn{3}{|l|}{ Satisfaction (n,\%) } \\
\cline { 3 - 5 } & & $\begin{array}{l}\text { Very } \\
\text { Satisfied }\end{array}$ & Satisfied & Dissatisfied \\
\hline Care bundle group & 29 & $22(75.9)$ & $6(20.7)$ & $1(3.44)$ \\
Control group & 29 & $12(42.4)$ & $15(51.7)$ & $2(6.9)$ \\
\hline$\chi^{2}$ & & 7.132 & \\
$P$ & & 0.028 & \\
\hline
\end{tabular}

than control group $(P<0.05)$. It indicated that the perioperative blood pressure in the two groups was controlled to a certain extent and reached or approached to normal ranges. The blood pressure control in the care bundle group was more effective than the control group.

The care bundle for the nursing care of $\mathrm{AD}$ patients involves not only the aspects of medical technology, monitoring skills and nursing practice, but also the perspective of humanistic care. According to the onset characteristics of AD patients, emotional support and a quiet and comfortable medical environment are used to reduce blood pressure rise caused by pain and anxiety. ${ }^{28}$ The target goal of blood pressure control was set, and an infusion micropump was used to inject vasoactive drugs to control blood pressure. A three-in-one integrated blood pressure management model, ${ }^{29}$ including the doctors, nurses and patients, was implemented during the perioperative period. They will work together to keep the patient's blood pressure at a stable level, which is the primary guarantee for successful surgery. It has been reported that the appliance this model has significantly improved the blood pressure control and the satisfaction of the medical staff with the work flow. ${ }^{30}$ This conclusion is consistent with the results of this study, indicating that the blood pressure control strategy in our study has good effect.
AD surgery needs to be performed with the support of $\mathrm{CPB}$. When establishing $\mathrm{CPB}$, it is necessary to reduce the patient's body temperature to moderate hypothermia, which provides effective brain protection and does not increase the complications of spinal cord and abdominal organs. ${ }^{31}$ When the blood vessel replacement is completed, the circulation is opened, and the heart needs to be warmed up to the normal body temperature range for the re-beating. Although this can be achieved by an extracorporeal circulation machine, comprehensive rewarming measures must be taken before the rectal temperature and nasopharyngeal temperature $\geq 36^{\circ} \mathrm{C}$ to fully ensure the timeliness of adjustment and prevent various complications caused by intraoperative hypothermia. ${ }^{32}$ Our results showed that the postoperative $\mathrm{T}$ and the $\mathrm{pH}$ value were different between the two groups, indicating that the integrated rewarming method in the care bundle can effectively maintain the $\mathrm{T}$ and $\mathrm{PH}$ value of $\mathrm{AD}$ patients during and after operation. Local aortic intima tearing and bleeding form intermural hematoma, which is prone to secondary damage to the patient due to secondary systemic pathophysiological changes, including secondary bleeding, low temperature, acidosis, and a vicious circle. ${ }^{33}$ Therefore, it is essential to actively prevent hypothermia. The comprehensive rewarming method has played a positive role in the control of $\mathrm{T}$ and $\mathrm{PH}$ in AD patients. The results of this study showed that the intraoperative bleeding volume in the care bundle group was lower than control group. This indicated that blood pressure control and intraoperative rewarming strategies cooperate with each other to reduce the blood vessel pressure caused by hypertension, thus reducing bleeding. Moreover, the normal body temperature maintained by rewarming can maintain the activity of various coagulation factors, prothrombin and platelets to effectively reduce the amount of bleeding. It is consistent with the conclusion of Wavra et al. ${ }^{34}$ Emergency surgery for ATAAD is associated with high risk for PTSD because of high blood pressure and pre-existing diseases of 
the aorta, which seems to negatively affect physical and mental well-being. ${ }^{35}$

During AD surgery, the application of CPB, deep hypothermia circulatory arrest and large amounts of blood product infusion will lead to further aggravation of inflammation and coagulation disorders. Cytokines of IL2, IL-6 and IL-10 are important indicators to evaluate the immune status of the body. ${ }^{36}$ Comprehensive rewarming can cause benign changes in cytokine levels, to a certain extent, inhibit the perioperative inflammatory response in $\mathrm{AD}$ patients, thereby reducing the incidence of infection and the risk of organ dysfunction. ${ }^{37}$ Our results showed that the levels of IL-2 and IL-10 were higher while IL-6 level was lower in the care bundle group than control group. The levels of IL-2 and IL-10 showed an increasing trend, while IL-6 showed a downward trend in the care bundle group in T0, T1 and T2. In the control group, there were no significant differences in IL-2 and IL-6 levels in the three periods, while IL-10 levels showed an increasing trend at first and then decreasing. Thus, the comprehensive rewarming in care bundle intervention can promote the secretion of IL-2 and IL-10 and reduce the secretion of IL-6. IL-10 can inhibit the infiltration of lymphocytes and neutrophils, which is essential for the balance of the body's inflammatory response. ${ }^{13}$ IL-6 can infiltrate the aortic wall and eventually lead to systemic inflammatory response. $^{12}$ Therefore, the increased IL-2 and IL-10 levels and decreased IL-6 level have a certain inhibitory effect on the inflammation induced by the pathological characteristics of AD and the hypothermic cycle. The levels of IL-2, IL-6 and IL-10 in T1 period showed significant differences between the two groups. T1 is the most critical perioperative period of $\mathrm{AD} .^{38}$ Due to the large surgical trauma, heavy blood loss and low-temperature perfusion, it is easy to destroy the normal functional metabolism. ${ }^{39,40}$ Within $6 \mathrm{~h}$ after the operation, the body needs to adjust the immune system to prevent the inflammatory reaction to reach the balance of the internal environment, which is closely related to postoperative recovery. ${ }^{37}$

The results of the present study also showed that in the care bundle group, the bloodstream infection rate, the incidences of postoperative delirium and the postoperative recovery time were all significantly lower than control group. By maintaining body temperature, the normal circulation functions of important organs are guaranteed, which facilitates the metabolism of anesthetic drugs, effectively shortens the postoperative recovery time, and reduces the incidence of postoperative delirium. ${ }^{41,42}$ The
ICU stay time in the care bundle group was shorter than that in the control group, which was closely related to the improvement of nursing team's overall professional ability.

Due to the establishment of CBP and hemodynamic changes, ${ }^{14}$ hypothermia treatment and subsequent rewarming process induced ischemia-reperfusion injury $^{43}$ and ischemia and hypoxia caused by circulatoryarrest-induced poor tissue perfusion ${ }^{44}$ that are two highrisk factors for the occurrence of pressure ulcers in cardiovascular surgery. The incidence of stress injury in patients undergoing cardiovascular surgery reaches $24.8 \%{ }^{45}$ Stress injury may increase the physical and mental pain, prolong the recovery time, increase the workload of medical care, and result in additional costs. $^{46}$ The specialist nursing team in this study implemented a special model for the prevention of pressure ulcers, containing 7 elements. Consistent with previous studies, ${ }^{4-49}$ we showed that the intraoperative pressure ulcer rate in the care bundle group was significantly lower than control group, indicating that this skin protection model was effective in preventing AD operative pressure ulcers and could significantly reduce the incidence of pressure ulcers, thereby reducing postoperative complications. Furthermore, doctor satisfaction in the care bundle group was higher than control group, which was consistent with previous researches. ${ }^{15,50,51}$ They believed that it was very important to strengthen the training of nurses' comprehensive quality, such as theoretical knowledge, operation technology, risk awareness and emergency ability.

There are also some limitations in this study. First, the sample size is small. Second, only TAAD patients were included. The data may not be generalized to patients with other types of AS. Further studies with larger sample sizes are needed.

\section{Conclusions}

In the care bundle group, the HR value was stable before and after the operation, the SBP and DBP levels were decreased significantly, and the core temperature and $\mathrm{pH}$ value remained stable. In the care bundle group, the levels of IL-2 and IL-10 were increased, IL-6 level was decreased, and the intraoperative blood loss, incidence of pressure ulcers, postoperative delirium, bloodstream infection, recovery time and ICU stay time were all decreased. However, the doctor satisfaction was increased in the care bundle group. Therefore, care bundle is beneficial to 
nursing care of AD surgical treatment and can effectively promote recovery of $\mathrm{AD}$ patients.

\section{Relevance to Clinical Practice}

Cluster nursing has been applied in Aortic dissection surgery. It can effectively ensure the stability of intraoperative life indications and reduce the postoperative complications. Meanwhile, it can promote collaboration between doctors and nurses to give full play to team effectiveness. The rescue time of patients with TAAD is effectively shortened. The patient's blood pressure is more stable. The patients' temperature can be properly controlled according to the course of surgery. The skin is protected. In conclusion, the safety of patients is fully guaranteed.

\section{Abbreviations}

TAAD, type A aortic dissection; HR, heart rate; SBP, systolic blood pressure; DBP, diastolic blood pressure; $\mathrm{T}$, temperature; AD, aortic dissection; SBP, systolic blood pressure; IHI, Institute for Healthcare Improvement; ELISA, Enzyme linked immunosorbent assay; CAMICU, Confusion Assessment Method for the Intensive Care Unit; SD, standard deviation.

\section{Ethics Approval and Consent to Participate}

The study was reviewed and approved by the Ethics Committee of the Xinjiang Medical University. Written informed consent was obtained from every patient. A total of 161 patients with TAAD who underwent surgery in the Xinjiang Medical University from January 2018 to December 2019 were included in the study.

\section{Author Contributions}

LL is responsible for the guarantor of integrity of the entire study, study concepts and design, definition of intellectual content, literature research, clinical studies, experimental studies, data analysis, statistical analysis, manuscript preparation and editing and review; JQZ is responsible for the literature research, clinical studies, experimental studies, data acquisition; LKL and XQC are responsible for the data acquisition; YLL is responsible for the guarantor of integrity of the entire study, data analysis, statistical analysis, manuscript review. All authors contributed to data analysis, drafting or revising the article, gave final approval of the version to be published, agreed to the submitted journal, and agree to be accountable for all aspects of the work.

\section{Funding}

This study was funded by the Natural Science Foundation of Xinjiang Uygur Autonomous Region (Grant No. 2016D 01C259).

\section{Disclosure}

There are no potential conflicts of interest to disclose.

\section{References}

1. Evangelista A, Isselbacher EM, Bossone E, et al.; IRAD Investigators. Insights from the international registry of acute aortic dissection: a 20-year experience of collaborative clinical research. Circulation. 2018;137 (17):1846-1860. doi:10.1161/CIRCULATIONAHA.117.031264

2. Zhang C, Fa X, Huang Z. Analysis of related risk factors for neurological complications after type A aortic dissection. $J$ Southeast Univ. 2017;36:361-364.

3. Kurz SD, Falk V, Kempfert J, et al. Insight into the incidence of acute aortic dissection in the German region of Berlin and Brandenburg. Int J Cardiol. 2017;241:326-329. doi:10.1016/j.ijcard.2017.05.024

4. Howard DP, Banerjee A, Fairhead JF, Perkins J, Silver LE, Rothwell PM. Population-based study of incidence and outcome of acute aortic dissection and premorbid risk factor control: 10-year results from the Oxford Vascular Study. Circulation. 2013;127:2031-2037. doi:10.1161/CIRCULATIONAHA.112.000483

5. Sun L, Qi R, Zhu J, Liu Y, Chang Q, Zheng J. Repair of acute type A dissection: our experiences and results. Ann Thorac Surg. 2011;91:1147-1152. doi:10.1016/j.athoracsur.2010.12.005

6. Xu J, Hu H, Wang X. Characteristics of distal rupture of Standford B type aortic dissection in subacute stage and its effect on aortic remodeling in patients undergoing endovascular repair. Shandong Med. 2018;58:38-41.

7. Luo J, Liu H. Interpretation of the guidelines for diagnosis and treatment of aortic diseases by the European Society of Cardiology in 2014. Lingnan J Cardiovasc Dis. 2014;20:691-696.

8. Del Porto F, Di Gioia C, Tritapepe L, et al. The multitasking role of macrophages in Stanford type A acute aortic dissection. Cardiology. 2014;127:123-129. doi:10.1159/000355253

9. Ranasinghe AM, Bonser RS. Biomarkers in acute aortic dissection and other aortic syndromes. J Am Coll Cardiol. 2010;56:1535-1541. doi:10.1016/j.jacc.2010.01.076

10. Wen D, Du X, Dong JZ, Zhou XL, Ma CS. Value of D-dimer and $\mathrm{C}$ reactive protein in predicting inhospital death in acute aortic dissection. Heart. 2013;99:1192-1197. doi:10.1136/heartjnl-2013-304158

11. Zynda ER, Grimm MJ, Yuan M, et al. A role for the thermal environment in defining co-stimulation requirements for $\mathrm{CD} 4(+)$ $\mathrm{T}$ cell activation. Cell Cycle. 2015;14:2340-2354. doi:10.1080/ 15384101.2015.1049782

12. Duan $\mathrm{X}, \mathrm{Xu} \mathrm{Z}$. The role of inflammatory response in acute type A aortic dissection complicated with lung injury. Chin General Pract. 2015;13:172-174.

13. Manzanillo P, Eidenschenk C, Ouyang W. Deciphering the crosstalk among IL-1 and IL-10 family cytokines in intestinal immunity. Trends Immunol. 2015;36:471-478. doi:10.1016/j.it.2015.06.003

14. Lumbley JL, Ali SA, Tchokouani LS. Retrospective review of predisposing factors for intraoperative pressure ulcer development. J Clin Anesth. 2014;26:368-374. doi:10.1016/j.jclinane.2014.01.012

15. Liu Y, Yu J. Research progress of care bundle to prevent unplanned extubation of tracheal intubation. J Nurs Sci. 2019;34:106-110. 
16. Salama MF, Jamal W, Al Mousa H, Rotimi V. Implementation of central venous catheter bundle in an intensive care unit in Kuwait: effect on central line-associated bloodstream infections. J Infect Public Health. 2016;9:34 41. doi:10.1016/j.jiph.2015.05.001

17. Salmond SW, Echevarria M, Allread V. Care bundles: increasing consistency of care. Orthop Nurs. 2017;36:45-48. doi:10.1097/ NOR.0000000000000311

18. Huang B, Li Q, Wang G. Effect of cluster nursing on state of pre-operative patients with acute aortic dissection. J Hunan Univ Tradit Chin Med. 2018;38:224-227.

19. Bekkers JA, Raap GB, Takkenberg JJ, Bogers AJ. Acute type A aortic dissection: long-term results and reoperations. Eur J Cardiothorac Surg. 2013;43:389-396. doi:10.1093/ejcts/ezs342

20. Peterson ED, Albert NM, Amin A, Patterson JH, Fonarow GC. Implementing critical pathways and a multidisciplinary team approach to cardiovascular disease management. Am J Cardiol. 2008;102:47g-56g. doi:10.1016/j.amjcard.2008.06.011

21. Papadopoulos DP, Sanidas EA, Viniou NA, et al. Cardiovascular hypertensive emergencies. Curr Hypertens Rep. 2015;17:5. doi:10.1007/s11906-014-0515-z

22. Tang CJ, Chan SW, Zhou WT, Liaw SY. Collaboration between hospital physicians and nurses: an integrated literature review. Int Nurs Rev. 2013;60:291-302. doi:10.1111/inr.12034

23. Perl T, Peichl LH, Reyntjens K, Deblaere I, Zaballos JM, Bräuer A. Efficacy of a novel prewarming system in the prevention of perioperative hypothermia. A prospective, randomized, multicenter study. Minerva Anestesiol. 2014;80:436-443.

24. Dutra RA, Salomé GM, Alves JR, et al. Using transparent polyurethane film and hydrocolloid dressings to prevent pressure ulcers. $J$ Wound Care. 2015;24:268. doi:10.12968/jowc.2015.24.6.268

25. White DB, Braddock CH, Bereknyei S, Curtis JR. Toward shared decision making at the end of life in intensive care units: opportunities for improvement. Arch Intern Med. 2007;167:461-467. doi:10.1001/archinte.167.5.461

26. Guo H, Sun D, Liang T. Interpretation of common problems in the use of ICU fuzzy assessment method. Chin J Clin. 2017;45:108-110.

27. Du L, Hu Y. Application of three-level management model in operation room management. Chin J Mod Nurs. 2017;23:3675-3677.

28. Rui W. Perioperative nursing of patients with Stanford B type aortic dissection secondary surgery. Chin J Pract Nurs. 2019;35:268-272.

29. Mancia G, Fagard R, Narkiewicz K, et al. 2013 ESH/ESC Guidelines for the management of arterial hypertension: the Task Force for the management of arterial hypertension of the European Society of Hypertension (ESH) and of the European Society of Cardiology (ESC). J Hypertens. 2013;31:1281-1357.

30. Himmelfarb CR, Commodore-Mensah Y, Hill MN. Expanding the role of nurses to improve hypertension care and control globally. Ann Glob Health. 2016;82:243-253. doi:10.1016/j.aogh.2016.02.003

31. Ding T, Fu S, Li Z. Analysis of postoperative complications in 33 patients with acute type A aortic dissection Chinese. J Lab Diagnosis. 2017;21:517-519.

32. Putzu M, Casati A, Berti M, Pagliarini G, Fanelli G. Clinical complications, monitoring and management of perioperative mild hypothermia: anesthesiological features. Acta Biomed. 2007;78:163-169.

33. Zhao Z, Nie S, Liu Y. Advances in hypothermia management process for trauma patients. J Nurs. 2017;32:98-102.

34. Wavra T, Laux C, Guanci MM, et al. Clinical Q \& A: translating therapeutic temperature management from theory to practice. Ther Hypothermia Temp Manag. 2015;5:177-181. doi:10.1089/ ther.2015.29002.mkb
35. Adam U, Habazettl H, Graefe K, Kuppe H, Wundram M, Kurz SD. Health-related quality of life of patients after surgery for acute type A aortic dissection. Interact Cardiovasc Thorac Surg. 2018;27 (1):48-53. doi:10.1093/icvts/ivy036

36. Del Porto F, Proietta M, Tritapepe L, et al. Inflammation and immune response in acute aortic dissection. Ann Med. 2010;42:622-629. doi:10.3109/07853890.2010.518156

37. Kaukonen KM, Bailey M, Pilcher D, Cooper DJ, Bellomo R. Systemic inflammatory response syndrome criteria in defining severe sepsis. $N$ Engl J Med. 2015;372:1629-1638. doi:10.1056/ NEJMoa1415236

38. Clark BC, Berger JT, Berul CI, et al. Risk factors for development of ectopic atrial tachycardia in post-operative congenital heart disease. Pediatr Cardiol. 2018;39:459-465. doi:10.1007/s00246-017-1773-8

39. Nielsen DV, Torp-Pedersen C, Skals RK, Gerds TA, Karaliunaite Z, Jakobsen CJ. Intraoperative milrinone versus dobutamine in cardiac surgery patients: a retrospective cohort study on mortality. Crit Care. 2018;22:51. doi:10.1186/s13054-018-1969-1

40. Zhou R. Effect of Milrinone on cytokines and left ventricular function in patients after valve replacement for cardiopulmonary bypass. Chin J Mod Med. 2018;9:97-101.

41. Shenkman B, Budnik I, Einav Y, Hauschner H, Andrejchin M, Martinowitz U. Model of trauma-induced coagulopathy including hemodilution, fibrinolysis, acidosis, and hypothermia: impact on blood coagulation and platelet function. J Trauma Acute Care Surg. 2017;82(2):287-292. doi:10.1097/TA.0000000000001282

42. Zorrilla-Vaca A, Healy R, Grant MC, et al. Intraoperative cerebral oximetry-based management for optimizing perioperative outcomes: a meta-analysis of randomized controlled trials. Can J Anaesth. 2018;65:529-542. doi:10.1007/s12630-018-1065-7

43. Dong Y, Song L, Liu J. Research progress of intraoperative pressure injury in patients undergoing cardiovascular surgery. J Nurs Sci. 2019;34:15-18.

44. Hu J, Xing L, Yang Y. A multi-center study on high-risk factors for surgical pressure ulcers in surgical patients. J Nurs. 2018;33:11-14.

45. Lu CX, Chen HL, Shen WQ, Feng LP. A new nomogram score for predicting surgery-related pressure ulcers in cardiovascular surgical patients. Int Wound J. 2017;14:226-232. doi:10.1111/iwj.12593

46. Mehaffey JH, Politano AD, Bhamidipati CM, et al. Decubitus ulcers in patients undergoing vascular operations do not influence mortality but affect resource utilization. Surgery. 2017;161:1720-1727. doi:10.1016/j.surg.2017.02.002

47. Black J, Alves P, Brindle CT, et al. Use of wound dressings to enhance prevention of pressure ulcers caused by medical devices. Int Wound J. 2015a;12(3):322-327. doi:10.1111/iwj.12111

48. Black J, Clark M, Dealey C, et al. Dressings as an adjunct to pressure ulcer prevention: consensus panel recommendations. Int Wound J. 2015b;12:484-488. doi:10.1111/iwj.12197

49. Zhao Q, Xu Y, Jiang H. Summary of best evidence regarding prevention and management of medical device related pressure injuries. J Nurs. 2019;34:8-11.

50. Qian Y, Zeng T, Dong C. Knowledge, belief, and practice regarding prevention of unplanned extubation of tracheal intubation in ICU nurses. J Nurs. 2016;31:58-60.

51. Della Rocca G, Vetrugno L, Coccia C, et al. Preoperative evaluation of patients undergoing lung resection surgery: defining the role of the anesthesiologist on a multidisciplinary team. $J$ Cardiothorac Vasc Anesth. 2016;30(2):530-538. doi:10.1053/j.jvca.2015.11.018 


\section{Publish your work in this journal}

The International Journal of General Medicine is an international, peer-reviewed open-access journal that focuses on general and internal medicine, pathogenesis, epidemiology, diagnosis, monitoring and treatment protocols. The journal is characterized by the rapid reporting of reviews, original research and clinical studies across all disease areas. The manuscript management system is completely online and includes a very quick and fair peer-review system, which is all easy to use. Visit http://www.dovepress.com/ testimonials.php to read real quotes from published authors. 